Vol.6 No.1

\title{
UJI AKURASI SUPPORT RESISTANCE BERBASIS DATA CANDLESTICK PADA INDUSTRI PERTAMBANGAN YANG TERDAFTAR DI INDEKS LQ45
}

\section{Octavian G. Reeves, Ivonne S Saerang, Joubert B. Maramis}

Universitas Sam Ratulangi

A R T I C LE IN F O

Keywords: Technical analysis, Candlestick, Support Resistance and Fibonacci Retracement
Kata Kunci : Analisis Teknikal, Candlestick, Support Resistance dan Fibonacci Retracement.

Corresponding author:

Octavian G. Reeves

octaviangarry@gmail.com
The capital market is one indicator of a country's economic progress, which contributes to the economic development of a country. Which can be described as a country's wheels, the source of funds for companies that are the support of a country. This research was conducted with the goals of studying accuracy support resistance by using Fibonacci retracement indicators based on candlestick stock price movements. The type of research used consists of a type of quantitative research using secondary data that contains a graph of the stock price of the LQ45 index mining sector which then carried out a different sample dependent test.

The results of this study indicate that the support and resistance on the Fibonacci Retracement indicator has a difference with the selection price so that it can complete estimates of inaccurate support resistance.

Pasar modal merupakan salah satu indikator kemajuan perekonomian suatu negara, yang turut berperan serta menunjang perkembangan dan pertumbuhan ekonomi suatu negara. Yang dimana dapat di jadikan sebuah gambaran roda perekonomian suatu negara, sumber dana bagi beroperasinya perusahaan yang merupakan tulang punggung suatu Negara. Penelitian ini dilakukan dengan tujuan untuk mengetahui akurasi support resistance dengan menggunakan indikator Fibonacci retracement berbasis data candlestick pergerakan harga saham. Jenis Penelitian yang digunakan berupa jenis penelitian kuantitatif dengan menggunakan data sekunder berupa grafik pergerakan harga saham sektor pertambangan indeks LQ45 lalu dilakukann uji beda sampel dependen.

Hasil Penelitian ini menunjukan bahwa support dan resistance pada indikator Fibonacci Retracement memiliki perbedaan dengan harga penutupan sehingga dapat disimpulkan prediksi support resistance tidak akurat. 


\section{PENDAHULUAN}

\section{Latar Belakang}

Investasi merupakan penanaman modal dalam suatu perusahaan atau proyek yang bertujuan memperoleh keuntungan. Investasi memiliki beberapa hal yang harus dipertimbangkan sebelum memutuskan untuk memulai suatu investasi. Hal-hal yang harus dipertimbangkan antara lain; risiko, dana, wahana investasi, tujuan, jangka waktu dan keuntungan. Pasar modal merupakan tempat untuk menginvestasikan uang dengan cara membeli suratsurat berharga seperti saham ataupun obligasi. Pasar modal merupakan salah satu indikator kemajuan perekonomian suatu negara, yang turut berperan serta menunjang perkembangan dan pertumbuhan ekonomi suatu negara. Yang dimana dapat di jadikan sebuah gambaran roda perekonomian suatu negara, sumber dana bagi beroperasinya perusahaan yang merupakan tulang punggung suatu Negara. Pasar modal dikelola oleh Bursa Efek Indonesia (BEI). Harga saham terus bergerak mengikut penawaran dan permintaan. BEI mempunyai sebelas indeks, antara lain Indeks Harga Saham Gabungan (IHSG), Indeks Liquid 45 (LQ45),Indeks Sektoral, Jakarta Islamic Index (JII), Indeks Kompas 100, Indeks Bisnis -27, Indeks Pefindo-25, Indeks SRI-KEHATI, Indeks Papan utama,, Indeks Papan pengembangan, Indeks Individual. Dari kesebelas Indeks di Bursa Efek Indnesia terdapat indeks LQ45 yang merupakan salah satu indeks di Bursa Efek Indonesia (BEI), di mana indeks tersebut memiliki likuiditas dan kapitalisasi paling besar dibandingkan dengan indeks yang lain.

BEI menerbitkan daftar saham-saham yang tergabung dalam indeks LQ45 sebanyak dua kali dalam satu tahun. BEI menerbitkan daftar pertama berlaku pada bulan Februari hingga Juli. BEI kemudian menerbitkan daftar kedua berlaku untuk bulan Agustus hingga Januari tahun berikutnya. Indeks LQ45 pada periode tahun 2018 terdapat delapan saham perusahaan sektor pertambangan yang terdaftar dalam indeks LQ45. Peneliti tertarik untuk meneliti saham indeks LQ45 karena indeks LQ45 merupakan indeks yang memiliki nilai kapitalisasi besar (harga dan nilai transaksi saham tinggi) yang sangat berpengaruh terhadap IHSG. Nilai kapitalisasi pasar indeks saham LQ45 sebesar 70\% dari kapitalisasi pasar saham dan nilai transaksi dalam pasar saham. Dalam penelitian ini lebih fokus membahas indeks LQ45 pada perusahaan sektor Pertambangan. Peneliti tertarik untuk meneliti perusahaan sektor pertambangan karena pada awal tahun 2018 harga saham perusahaan sektor pertambangan naik seiring dengan harga komoditas dunia yang naik bahkan seorang senior equity brokerage MNC sekuritas Banjarmasin Herry Wachiendin di Banjarmasin Post "Berpendapat bahwa beberapa emiten sektor pertambangan memang saat ini mengalami kinerja baik didukung berbagai sentimen termasuk peluang ekspor dan baiknya harga komoditi dunia. Diperkirakan sampai akhir tahun 2018 sektor ini masih bagus". Namun pada bulan Oktober mulai mengalami penururnan yang signifikan sangat menarik untuk melihat pergerakan harga saham perusahaan sektor pertambangan selanjutnya melihat kinerja perusahaan sektor pertambangan yang baik dan didukung dengan sentimen positif untuk peluang ekspor. Dalam berinvestasi investor dapat mengetahui pergerakan harga saham di masa yang akan datang yaitu dengan melakukan analisa pergerakan harga saham sebelum melakukan investasi pada saham perusahaan tertentu, tentunya dengan mengetahui pergerakan harga saham suatu perusahaan kedepan dapat memberikan informasi pada investor untuk mengambil keputusan berinvestasi, Setiap pelaku pasar modal memerlukan suatu alat analisis untuk membantu dalam mengambil keputusan membeli atau menjual suatu saham (Susanto dan Sabardi, 2010:29). Dalam menganalisa pergerakan harga saham ada dua cara yaitu Analisis Fundamental dan Analisis Teknikal.

Saat ini banyak investor cenderung hanya menggunakan analisa fundamental untuk mengetahui pergerakan harga saham suatu perusahaan yaitu dengan melihat laporan keuangan suatu perusahaan, memang keputusan yang di ambil dari analisa fundamental memang baik, namun dalam pergerakan harga saham sangatlah volatile atau bergejolak sehingga untuk melihat pergerakan harga saham secara lebih spesifik diperlukan analisa teknikal karena analisa teknikal sendiri melihat pergerakan harga saham dari demand dan supply yang terjadi pada saat itu.

Maka dari itu pada penelitian ini, penulis tertarik untuk membahas mengenai analisis teknikal. Analisis teknikal merupakan suatu metodologi peramalan pergerakan harga saham dan meramalkan kecenderungan pasar di masa mendatang dengan cara mempelajari grafik harga saham, volume perdagangan dan indeks harga saham gabungan (Susanto dan Sabardi, 2010:30). Banyak grafik yang digunakan untuk analisis teknikal, namun yang sering digunakan adalah indikator grafik Candlestick. Candlestick adalah sebuah teknik untuk memetakan dan membaca pergerakan harga saham, komoditas dan forex. Teknik ini termasuk dalam kelompok analisis teknikal dan merupakan teknik tertua yang diciptakan oleh Munehisa Homma (Jepang, 1724-1803). Peneliti menggunakan 
indikator Candlestick sebagai alat untuk memberikan informasi pergerakan harga saham, karena indikator Candlestick memiliki pola-pola yang dapat memberikan sinyal reversal atau pembalikan arah dan juga sinyal continius atau berkelanjutan sehingga dapat menggambarkan keadaan pasar.

Pendekatan lain juga dibutuhkan untuk melihat kondisi pasar yang terjadi dalam suatu periode tersebut yaitu Fibonacci retracement, Fibonacci pertama kali diperkenalkan oleh seorang ahli matematika abad pertengahan asal Italia. Namanya Leonardo Fibonacci yang berasal dari kota Pisa. Fibonacci retracement merupakan indikator yang sering digunakan oleh para trader dengan melihat batas support dan resistance suatu pergerakan harga saham maupun forex. Para trader menggunakan level-level yang diberikan oleh Fibonacci retracement untuk membantu menentukan kisaran area yang potensial sebagai support dan resistance. Level support dan resistance merupakan level yang digunakan untuk menahan harga apabila minat beli sangat besar sehingga para penjual akan menjual barangnya (saham) di harga tahanannya supaya harga tidak melambung tinggi (David, 2010:28) dalam Putra (2013).

\section{Tujuan Penelitian}

Tujuan penelitian ini adalah untuk mengetahui perbedaan:

Signifikan antara harga saham hasil presiksi support dan resistance berdasarkan data candlestick dengan closing price perusahaan pertambangan yang terdaftar di indeks Lq45 periode Oktober.

\section{Signalling Theory}

\section{TINJAUAN PUSTAKA}

Signalling theory atau teori sinyal menjelaskan mengapa perusahaan mempuyai dorongan untuk memberikan informasi laporan keuangan pada pihak eksternal. Dorongan perusahaan untuk memberikan informasi karena terdapat asimetri informasi antara perusahaan dan pihak luar karena perusahaan mengetahui lebih banyak mengenai perusahaan dan prospek yang akan datang daripada pihak luar (investor dan kreditor). Menurut T. C. Melewar menyatakan Teori Sinyal menunjukkan bahwa perusahaan akan memberikan sinyal melalui tindakan dan komunikasi. Perusahaan ini mengadopsi sinyal-sinyal ini untuk mengungkapkan atribut yang tersembunyi untuk para pemangku kepentingan (Indojasa.com).

\section{Teori Efisiensi Pasar Hipotesis}

Teori eficiency market pertama kali ditemukan dalam penelitian yang dilakukan oleh Bachelier pada tahun 1900 yang ingin mengetahui apakah harga saham berfluktuasi secara acak atau tidak. Teori efisiensi pasar hipotesisi di bagi dalam tiga bentuk utama yaitu :

1. Efisiensi pasar bentuk lemah (weak form) Pasar dikatakan efisien dalam bentuk yang lemah adalah apabila harga-harga dari saham atau sekuritas mencerminkan secara penuh (fully reflect) informasi masa lalu.

2. Efisiensi pasar bentuk setengah kuat (semistrong form) Pasar dapat dikatakan efisien setengah kuat jika harga-harga sekuritas saham secara penuh mencerminkan semua informasi yang dipublikasikan (all publicly available information) termasuk informasi yang berada di laporan-laporan keuangan.

3. Efisiensi pasar bentuk kuat (strong form) Pasar dapat dikatakan efisien dalam bentuk yang kuat apabila hargaharga sekuritas saham secara penuh mencerminkan seluruh informasi yang tersedia termasuk informasi yang sangat rahasia sekalipun. (Datakata.wordpress.com).

\section{Indeks LQ45}

Indeks LQ45 adalah indeks yang tediri dari 45 emiten dengan likuidasi (Liquid) tinggi,yang diseleksi melalui beberapa kriteria pemilihan. Selain penilaian atas likuiditas, seleksi atas emiten-emiten tersebut juga mempertimbangkan kapitalisasi pasar.

\section{Analisis Teknikal}

Analisis teknikal merupakan suatu metodologi peramalan pergerakan harga saham dan meramalkan kecenderungan pasar di masa mendatang dengan cara mempelajari grafik harga saham, volume perdagangan dan indeks harga saham gabungan Susanto dan Sabardi (2010:30). Analisis teknikal memiliki prinsip- prinsip 
dalam penerapannya yaitu segalanya didiskontokan dan digambarkan dalam harga-harga pasar, hargaharga bergerak dalam suatu kecenderungan yang terus berlangsung, kejadian pasar selalu berulang kembali.

\section{Candlestick}

Candlestick adalah sebuah teknik untuk memetakan dan membaca pergerakan harga saham,komoditas dan forex. Teknik ini termasuk dalam kelompok analisis teknikal dan merupakan teknik tertua yang diciptakan oleh Munehisa Homma (Jepang, 1724-1803). Grafik tersebut awalnya digunakan untuk memprediksi pergerakan hargaharga beras pada masanya dan masa yang belum terjadi dengan menggunakan harga-harga yang sudah lampau (Vibby, 2006:1) dalam Cahyadi (2012).

\section{Fibonacci retracement}

Pendekatan dengan rasio Fibonacci dalam analisis teknikal perdagangan saham telah banyak digunakan oleh para analis. Pergerakan saham salah satunya dipengaruhi oleh perilaku manusia. Perilaku manusia merupakan salah satu hukum alam. Hukum alam dapat diukur dengan rasio Fibonacci (Poulos, 2004:2) dalam Putra (2013).

\section{Penelitian Terdahulu}

Effendy (2016) dalam penelitiannya yang berjudul Pengaruh Yesterday Open dan Close Price terhadap Today Open Price dengan Memanfaatkan Pivot Level untuk Memprediksi Pergerakan Valuta Asing, Hasil penelitian menemukan adanya korelasi yang signifikan antara Yesterday Close Price dan Today Open Price dalam penentuan area resistance dan support. Penelitian ini dapat menjadi dasar dalam pengembangan Sistem Penunjang Keputusan dalam bertransaksi forex online berupa Expert Advisor.

Putra (2013) dalam penelitiannya yang berjudul Analisis Teknikal Pergerakan Harga Saham Individual Perusahaan Pertambangan Yang Terdaftar Pada Lq 45 Dengan Menggunakan Indikator Candlestick,Pendekatan Rasio Fibonacci, Dan Analisis Fuzzy Logic, Hasil analisis teknikal pada pergerakan saham menunjukan bahwa selama periode tahun 2012 pergerakan saham mengalami trend menurun. Trend menurun merupakan sinyal yang baik bagi calon investor yang ingin membeli saham dari sektor pertambangan. Saham saham yang mengalami trend menurun menunjukan ada dua saham yang direkomendasikan lebih daripada kedelapan saham yang lain.

Junaidi (2013) dalam penelitiannya yang berjudul Analisis Teknikal Saham Pt. Kalbe Farma Dengan Candlestick, Bollinger Band Dan Stochastic Oscillator, Hasil dari penelitian ini diketahui bahwa telah terjadi 19 kali transaksi buy dan 10 kali transaksi sell. Terjadi stop loss sebanyak 2 kali ditanggal 5 November dan 26 Desember 2012 sedangkan take profit terjadi sebanyak 5 kali ditanggal 8 Agustus, 7 September dan 23 November 2012 serta 31 Januari dan 25 April 2013. Ada pun 3 kali transaksi penjualan ditanggal 8 Juni 2012, 13 Juli 2012 dan 30 April 2013 yang tidak mengalami take profit karena harga tidak naik ditambah biaya komisi, namun tetap dilakukan ketika terjadi sinyal jual sesuai rencana dan strategi perdagangan. Jumlah seluruh biaya komisi (fee) yang ditanggung selama 1 tahun sebesar Rp 2.884.663,-, yang terdiri dari fee beli Rp 1.190.155,- dan fee jual Rp 1.694.508,-, sedangkan gain selama 1 tahun sebesar 10,87\%. Dari hasil penelitian yang dilakukan diperoleh simpulan bahwa simulasi backtesting ini tidak mencapai keuntungan yang ditargetkan sebesar $30 \%$. 


\section{Model Penelitian}

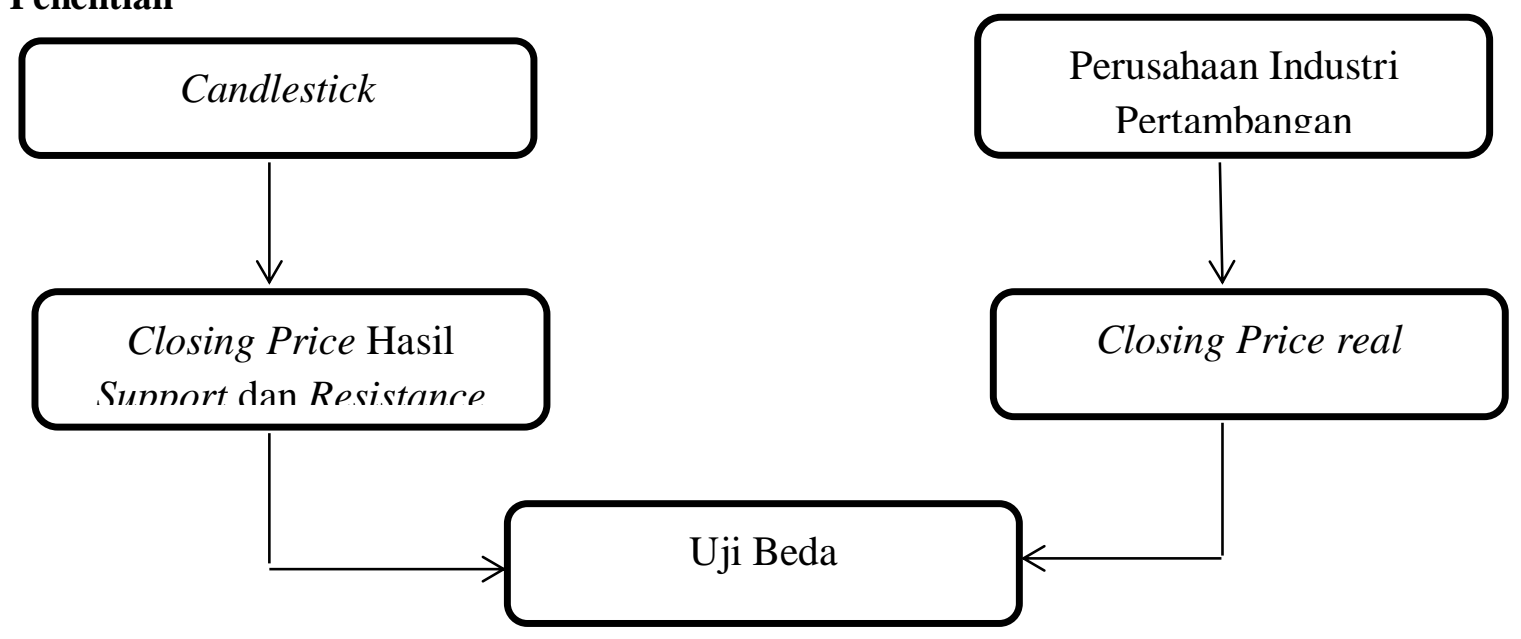

\section{Gambar 1. Kerangka Konseptual \\ Sumber: Kajian Teoritik 2019}

\section{Hipotesis Penelitian}

H0: Tidak terdapat perbedaan signifikan antara harga saham hasil presiksi support dan resistance berdasarkan data candlestick dengan closing price perusahaan pertambangan yang terdaftar di indeks Lq45 periode Oktober H1: Terdapat perbedaan signifikan antara harga saham hasil presiksi support dan resistance berdasarkan data candlestick dengan closing price perusahaan pertambangan yang terdaftar di indeks Lq45 periode Oktober

\section{METODE PENELITIAN}

\section{Pendekatan Penelitian}

Menggunakan jenis penelitian Komparatif yaitu penelitian yang di maksudkan untuk menguji adanya perbedaan yang terjadi antara dua variable atau lebih dengan metode Kuantitatif menggunakan data pergerakan harga saham setiap hari kerja pada setiap perusahaan sektor pertambangan indeks LQ45 periode Oktober 2018

\section{Populasi, Sampel, dan Teknik Sampling}

Populasi dalam penelitian ini yaitu semua perusahaan tambang yang terdaftar di indeks lq45 periode Agustus 2018-Januari 2019 dengan penggunaan sampel jenuh sehingga di dapat delapan perusahaan tambang Untuk dilihat pergerakan harga sahamnya setiap hari kerja bursa selama bulan Oktober yaitu 23 hari pada delapan perusahaan pertambangan di indeks LQ45 ( $\mathrm{n}=184)$.

\section{Jenis Dan Sumber Data}

Data yang digunakan dalam penelitian ini adalah data sekunder. Data sekunder adalah data primer yang telah diolah lebih lanjut dan disajikan oleh pihak pengumpul data primer atau pihak lain, data primer disajikan antara lain dalam bentuk table-tabel, diagram-diagram atau juga grafik. Sumber data yang digunakan dalam penelitian ini adalah data sekunder yang diperoleh dalam bentuk grafik atau chart pergerakan harga saham (Software Chartnexus).

\section{Teknik Pengumpulan Data}

Pada penelitian ini metode pengumpulan data bersifat dokumenter. Peneliti langsung dan mengunduh grafik pergerakan saham indeks LQ45 sektor pertambangan dari aplikasi atau software Chartnexus selama periode Oktober 2018.

\section{Desain Penelitian}


Desain penelitian dalam penelitian ini yaitu menggunakan uji komparatif merupakan penelitian yang di maksudkan untuk menguji adanya perbedaan yang terjadi antara dua variable atau lebih. Komparasi adalah penyelidikan deskriptif yang berusaha mencari pemecahan melalui analisis tentang hubungan sebab akibat, yakni memilih faktor-faktor tertentu yang berhubungan dengan situasi atau fenomena yang diselidiki dan membandingkan satu faktor dengan faktor lain.Surakhmad, W (1986:84) dalam Meykalian, R (2016). Dalam penelitian ini yang akan di uji apakah terdapat perbedaannya yaitu closing price real dan closing price hasil support dan resistance dari indikator fibonacci retracements.

\section{Definisi Operasional Variabel}

1. Harga penutupan (Closing Price) adalah harga yang muncul pada saat bursa tutup. Harga penutupan bursa sangat penting karena menjadi acuan untuk harga pembukaan keesokan harinya. Harga penutupan biasanya digunakan untuk memprediksi harga pada periode selanjutnya. Memprediksi harga saham dalam dunia investasi sangatlah penting karena dengan demikian para investor dan trader dapat mengambil keputusan membeli saham atau menjual sahamnya. Harapannya tentu saja agar bisa mendapatkan keuntungan yang maksimal. Untuk melihat harga penutupan bursa bisa dilihat dalam satuan rupiah pada setiap perusahaan yang terdaftar di bursa efek Indonesia. Dan pada penelitian ini akan meneliti closing price pada perusahaan pertambangan yang terdaftar di indeks LQ45.

2. Support dan resistance pada pergerakan harga saham. Support adalah batas bawah pergerakan harga, pada saat ini pembeli memiliki peluang yang lebih besar untuk kembali muncul melakukan pembelian saham karena para pembeli beranggapan bahwa harga sudah pada posisi murah sehingga membuat harga cenderung kembali memantul ke atas (rebound). Resistance adalah batas atas pergerakan harga, pada saat ini penjual memiliki peluang yang lebih besar untuk kembali muncul melakukan penjualan saham karena para penjual beranggapan bahwa harga sudah pada posisi mahal dan para penjual sudah mendapatkan keuntungan sehingga membuat harga cenderung memantul ke bawah (bounce back).

3. Candlestick chart sama halnya dengan bar chart terbentuk dari harga pembukaan, harga tertinggi, harga terendah, dan harga penutupan hanya saja badan atau body dari candlestick dibedakan warnanya antara naik (menguat) dengan harga yang turun (melemah) sehingga lebih mudah untuk dilihat secara visual dibandingkan dengan bar chart, garis di luar badan candle tersebut mencerminkan harga tertinggi dan harga terendah ditandai dengan garis yang di sebut upper shadow untuk harga tertinggi yang berada di atas body candle dan lower shadow untuk harga terendah yang berada di bawah body candle.

\section{Teknik Analisis Data}

Pada penelitian ini penulis menggunakan terknik analisis uji beda sampel dependen atau dependent sample t-test atau sering diistilakan dengan paired sampel t-test, adalah jenis uji statistika yang bertujuan untuk membandingkan rata-rata dua grup yang saling berpasangan (freelearningji.wordpress.com).

\section{Hasil Penelitian}

HASIL PENELITIAN DAN PEMBAHASAN

\section{Uji Beda}

Paired Samples Test

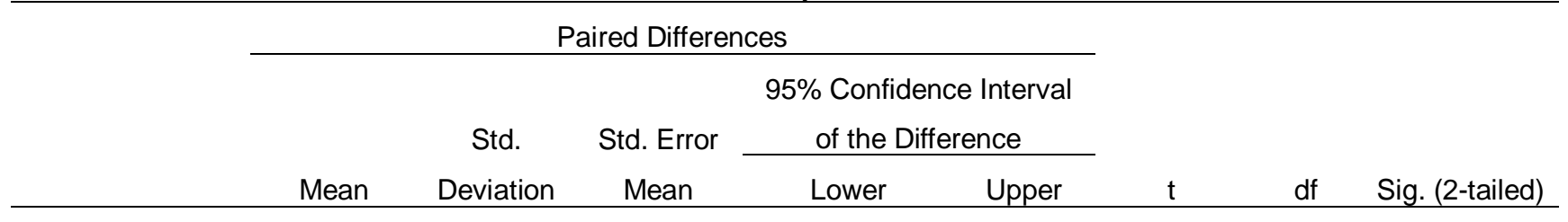




\begin{tabular}{|c|c|c|c|c|c|c|c|c|c|}
\hline Pair & EXPECTE & \multirow{5}{*}{-159.228} & \multirow{5}{*}{269.558} & \multirow{5}{*}{19.872} & \multirow{5}{*}{-198.436} & \multirow{4}{*}{-120.020} & \multirow{5}{*}{-8.013} & \multirow{5}{*}{183} & \multirow{5}{*}{.000} \\
\hline \multirow[t]{4}{*}{1} & D PRICE & & & & & & & & \\
\hline & LEVEL & & & & & & & & \\
\hline & CLOSING & & & & & & & & \\
\hline & PRICE & & & & & & & & \\
\hline
\end{tabular}

Sumber : SPSS data diolah, 2019

Pada Tabel 1 terlihat bahwa probabilitas Expected Price Level 78.6\% dan Closing Price adalah 0.000.Oleh karena itu nilai p $0.000<0.05$, Maka dapat disimpulkan bahwa Expected Price Level $78.6 \%$ dan Closing Price berpengaruh signifikan artinya Expected Price Level $78.6 \%$ memiliki perbedaan terhadap Closing Price secara umum pada delapan perusahaan tambang yang terdaftar di indeks LQ45.

\section{Pembahasan}

Hasil Penelitian diperoleh angka signifikansi $0.000<0.05$, sehingga secara keseluruhan Expected Price Level 78.6\% mempunyai perbedaan terhadap Closing Price dan dari hasil olah data diatas juga dapat dilihat juga secara parsial bahwa delapan perusahaan tambang yang menjadi objek menunjukan hasil signifikan yang berarti Expected Price Level 78.6\% memiliki perbedaan terhadap Closing Price, perbedaan yang terjadi antara Expected Price Level 78.6\% dan Closing Price memiliki arti bahwa indikator Fibonacci Retracement yang menunjukan level support resistance disimpulkan tidak akurat dalam mempresiksi pergerakan harga saham delapan perusahaan pertambangan yang terdaftar di indeks LQ45 pada bulan Oktober. Hal ini dipengaruhi oleh sentimen eksternal dimana pergerakan harga komoditas dunia mengalami penurunan dan juga perang dagang antara Amerika Serikat dengan Tiongkok sehingga mempengaruhi juga pergerakan harga-harga komoditas yang berdampak pada pergerakan harga saham perusahaan pertambangan menjadi tidak stabil dan juga lebih sulit untuk diprediksi.

Hasil ini mengindikasikan bahwa harga saham dalam pasar modal bekerja dengan efisien dimana pasar menerima informasi yang relevan sesuai dengan Teori Efisiensi Pasar Hipotesis. Teori Efisiensi Pasar Hipotesis merupakan suatu pasar bursa efek yang diperdagangkan merefleksikan semua informasi yang terjadi dengan cepat dan akurat, Dalam merefleksikan semua informasi yang terjadi teori efisien pasar hipotesis dibagi dalam tiga bentuk utama yaitu efisiensi pasar bentuk lemah, efisiensi pasar bentuk setengah kuat, dan efisiensi pasar bentuk kuat. Dan jika dilihat dari segi perusahaan pada penelitian ini yaitu perusahaan tambang yang terdaftar di LQ45 memperlihatkan bahwa perusahaan- perusahaan ini sangat meresponi signal yang terjadi secara global sehingga sesuai dengan Signalling Theory.

Signalling Theory adalah teori yang melihat pada tanda-tanda tentang kondisi yang menggambarkan suatu perusahaan, Signalling Theory menyatakan bahwa perusahaan yang berkualitas baik dengan sengaja akan memberikan sinyal pada pasar, dengan demikian pasar dapat membedakan perusahaan yang berkualitas baik dan buruk. Agar sinyal tersebut baik, maka harus dapat ditangkap pasar dan diapresiasikan baik serta tidak mudah ditiru oleh perusahaan yang memiliki kualitas yang buruk. Informasi yang dipublikasikan sebagai suatu pengumuman akan memberikan signal bagi para investor dalam pengambilan keputusan investasi. Jika pengumuman tersebut mengandung nilai positif, maka diharapkan akan beraksi pada waktu pengumuman terebut di terima oleh pasar (Martono dan Harjito, 2007 : 11) dalam Liogu (2015).Hasil ini didukung oleh penelitian Liogu (2015).

\section{Kesimpulan}

\section{PENUTUP}

1. Oleh karena hasil Expected Price Level 78.6\% dengan Closing Price secara umum menunjukan hasil yang signifikan ( Probabilitas 0.000 ) maka dapat disimpulka bahwa Expected Price Level $78.6 \%$ memiliki perbedaan terhadap Closing Price yang artinya indikator Fibonacci Retracement yang menunjukan level-level support resistance tidak akurat dalam memprediksi pergerakan harga saham pada bulan Oktober 2018. 
2. Secara parsial menunjukan hasil bahwa Expected Price Level $78.6 \%$ dengan Closing Price juga menunjukan hasil yang signifikan pada PT.Adaro Energy Tbk menunjukan probabilitas 0.024, PT. Aneka Tambang Tbk menunjukan probabilitas 0.000 , PT Elnusa Tbk menunjukan probabilitas 0.000, PT. Vale Indonesia Tbk menunjukan probabilitas 0.000, PT. Indika Energy Tbk menunjukan probabilitas 0.000, PT. Indo Tambangraya Megah Tbk menunjukan probabilitas 0.001, PT. Medco Energy Internasional Tbk menunjukan probabilitas 0.005, dan PT Tambang Batu Bara Bukit Asam (PERSERO) Tbk menunjukan probabilitas 0.000.

3. Dari hasil analisa maka H1 diterima namun indikator Fibonacci Retracement yang menunjukan level-level support resistance disimpulkan tidak akurat karena memiliki perbedaan terhadap Closing price pada bulan Oktober.

\section{Saran}

Saran yang dapat diberikan berdasarkan penelitian dan pembahasan ini adalah bagi peneliti lain untuk dapat mengkombinasikan beberapa variabel lain dan juga mempertimbangkan jangka waktu yang akan di teliti karena dengan demikian mungkin dapat memberikan hasil yang lebih akurat dan bagi investor juga demikian agar mengkombinasikan beberapa indikator analisa teknikal dan juga memperhatikan waktu agar mendapatkan hasil prediksi yang lebih akurat.

\section{DAFTAR PUSTAKA}

Alalaya, M., dan Almahameed, M, A. (2018). Fibonacci Retracement and Elliot Waves to Predict Stock Market Prices: Evidence from Amman Stock Exchange Market. International Journal of Applied Science and Technology Vol. 8, No. 3, September 2018 doi:10.30845/ijast.v8n3p7. http://www.ijastnet.com/journals/Vol 8 No 3 September 2018/7.pdf diakses pada Januari 2019

Bursa Efek Indonesia. (2018) Pengertian Indeks LQ45. Indeks. http://www.idx.co.id/produk/indeks/diakses pada 29 Oktober 2018

Blindtrader.

Kamus

Candlestick.

Candlestick. https://www.kaskus.co.id/thread/57689ccc947868492c8b4568/kamus-candlestick/ diakses pada 29 Oktober 2018

Cahyadi, Y. (2012) Analisis Pola Grafik Candlestick Pada Pergerakan EUR/USD. Jurnal.http://journal.binus.ac.id/index.php/BBR/article/viewFile/1357/1218 diakses pada 29 Oktober 2018

Daftar Perusahaan yang termasuk dalam Indeks Lq45 periode Agustus 2018- Jaunari 2019 http://www.idx.co.id/media/2748/20180726_lq45_aug18-jan19.pdf diakses pada 29 Oktober 2018

Effendy, M, Y. (2016). Pengaruh Yesterday Open Dan Close Price Terhadap Today Open Price Dengan Memanfaatkan Pivot Level Untuk Memprediksi Pergerakan Valuta Asing Jurnal Manajemen Magister, Vol 02. No.01, Januari 201636 Informatics .Https://Media.Neliti.Com/Media/Publications/209569-None.Pdf diakses pada 7 November 2018

Firmansyah, D, M. (2015) Implementasi Penggunaan Sistem Pakar Pada Trading Forex Jenis Locco. Artikel. http://mahasiswa.dinus.ac.id/docs/skripsi/jurnal/15197.pdf diakses pada 7 November 2018

Gaucan, V. (2011). How to use Fibonacci retracement to predict forex market. ISSN 2069-5934 ScientificPaper.org. http://www.scientificpapers.org/wp-content/files/volume1_issue_2_2011.pdf diakses pada 19 Januari 2019

Gupta, N. (2011). Fibonacci Retracements and Self-Fulfilling Prophecy. DigitalCommons@Macalester College. Jurnal.

http://digitalcommons.macalester.edu/cgi/viewcontent.cgi?article=1041\&context=economics honors proje cts diakses pada 19 Januari 2019 
Hadi, A., Santoso, M. dan Lim, R. (2013) Pembuatan Market Expert Advisor pada Currency Market menggunakan Fibonacci, Stochastic dan MACD Indicator . Jurnal Dimensi Teknik Elektro Vol. 1, No. 1, (2013) 55-60 https://media.neliti.com/media/publications/182972-ID-pembuatan-market-expert-advisor-pada-cur.pdf diakses pada 29 Oktober 2018

Hendarsih, I. (2016) Analisis Perubahan Harga Saham Dengan Menggunakan Grafik Candlestick. MONETER, VOL. III NO. 2 OKTOBER 2016 http://ejournal.bsi.ac.id/ejurnal/index.php/moneter/article/view/1199/957 diakses pada 29 Oktober 2018

Hartono, W, dan Widjojo, A. (2018) Analisis Fundamental Dan Teknikal Sebelum Dan Sesudah Merger Pada Perusahaan Ciputra Development. JRAK, Volume 14, No 1 Pebruari 2018 http://ejournalfb.ukdw.ac.id/index.php/jrak/article/view/298/275 diakses pada 29 Oktober 2018

Indojasa.com. (2018). Pengertian Teori Sinyal atau Signalling Theory Menurut Ahli. Artikel. https://www.indosaja.com/2018/05/30/pengertian-teori-sinyal-signalling-theory/ diakses pada 11 November 2018.

Ilhamzen. (2013). Uji t dua sampel. Artikel. https://freelearningji.wordpress.com/2013/04/06/uji-t-dua-sampel/ diakses pada 8 November 2018

Junaidi, E. (2013) Analisis Teknikal Saham Pt. Kalbe Farma Dengan Candlestick, Bollinger Band Dan Stochastic Oscillator. Jurnal http://thesis.binus.ac.id/doc/Lain-lain/2012-2-00382 AK\%20WorkingPaper002.pdf diakses pada 29 Oktober 2018

Kusumawardana, V, (2016). Komparasi Strategi Investasi Aktif Dan Pasif Untuk Optimalkan Return Saham Yang Terdaftar Di Bursa Efek Indnesia (Studi Pada Perusahaan Idx 30 Periode 2012 -2015) Program Studi MmtIts, $\quad$ Surabaya, $30 \quad$ Juli 2016.Http://Mmt.Its.Ac.Id/Download/Semnas/Semnas\%20xxv/Mi/16.\%20prosiding\%20venus\%20kusuma \%20wardana\%20-\%20ok.Pdf diakses pada 7 November 2018

Liogu, S, J. (2015). Reaksi Pasar Modal Terhadap Pengumuman Kenaikan Harga BBM Atas Saham LQ45 Pada Tanggal 1 November 2014. Skripsi

Lu, T, H. (2014). The profitability of candlestick charting in the Taiwan stock market. Department of Economics, National Tsing Hua University, No. 101, Section 2, Kuang-Fu Road, Hsinchu 30013,Taiwan, ROC . https://www.sciencedirect.com/science/article/pii/S0927538X13000735 diakses pada 19 Januari 2019

Muchlishin, I, S. (2011) Prediksi Harga Saham Dalam Perspektif Analisis Teknikal (Studi Pada Jakarta Islamic Index (Jii) Tahun 2007-2011). Skripsi.Repository.Uinjkt.Ac.Id/Dspace/.../Iham\%20syaiful\%20muchlishinFsh.Pdf diakses pada 7 November 2018

Meikalian, R. (2016). Studi Komparasi Standar Pelayanan Minimal (Spm) Bus Trans Jogja. Skripsi. http://ejournal.uajy.ac.id/8883/3/2MTS02204.pdf diakses pada 8 November 2018

Mukti, W., dan Wibawa, R, S. (2017). Technical Analisys Dan Bitcoin Traders. Jurnal Trading Volume 1, Maret 2017. bitcoinnewsindo.com/wp-content/.../03/Technical-Analisys-dan-Bitcoin-Traders.pdf. diakses pada 7 November 2018

Ong, E. (2016). Technical Analysis For Mega Profit. Jakarta : PT. Gramedia Pustaka Utama.

Putra, M. W. K. (2013) Analisis Teknikal Pergerakan Harga Saham Individual Perusahaan Pertambangan Yang Terdaftar Pada Lq 45 Dengan Menggunakan Indikator Candlestick, Pendekatan Rasio Fibonacci, Dan Analisis 
http://eprints.uny.ac.id/16243/1/MUHAMMAD\%20WAHYU\%20NIM.\%2009412141001.pdf diakses pada 29 Oktober 2018

Prabhata, A. (2012) Efektifitas Penggunaan Analisis Teknikal Stochastic Oscillator Dan Moving Average Convergence-Divergence (Macd) Pada Perdagangan Saham-Saham Jakarta Islamic Index (Jii) Di Bursa Efek Indonesia. Sinergi Kajian Bisnis Dan Manajemen Vol. 13 No. 1, Juni 2012,ISSN 1410 9018.http://www.jurnal.uii.ac.id/Sinergi/article/view/3825 diakses pada 29 Oktober 2018

Pribadi, S, A. (2016) Analisis Teknikal Sebagai Dasar Pengambilan Keputusan Dalam Transaksi Saham (Studi Pada Peusahaan Manufactur di Jakarta Islamic Index Januari 2016-Juni 2016). Skirpsi http://etheses.uinmalang.ac.id/5949/1/13510163.pdf diakses pada 29 Oktober 2018

Riyanto, P. (2018) Pengertian Manajemen Keuangan Menurut Para Ahli terlengkap, Artikel dari Parta Setiawan (2018)._ https://www.gurupendidikan.co.id/pengertian-manajemen-keuangan-menurut-para-ahliterlengkap/diakses pada 30 Oktober 2018

Sobirin, A. (2016). Penerapan Analisa Teknikal Untuk Memprediksi Pergerakan Harga Saham Pada Perusahaan Lq45 Dengan Menggunakan Indikator Rsi, Macd, Stochastic, Fibonacci Dan Pivot Point. Skripsi. http://eprints.unwahas.ac.id/851/1/cover.pdf diakses pada 7 November 2018

Susanto, D. dan Sabardi, A. (2010) Analisis Teknikal di Bursa Efek. edisi kedua, Yogyakarta: UPP STIM YKPN.

Saham Ok. (2018) Pengertian Indeks LQ45. Indeks LQ45. https://www.sahamok.com/bei/indeks-bursa/indeks-lq45/ diakses pada_29 Oktober 2018

Tabar,S., Gholamalitabar, M., Najjar,L., dan Volkman, D. (2016) Risk Control In Algorithmic Trading Using Fibonacci Series. International Journal of Social Science and Economic Research. ISSN: 2455-8834 Volume:01, Issue:06 . http://ijsser.org/uploads/ijsser 01 50.pdf diakses pada 19 Januari 2019

Tribunnews saham baru Indeks Lq45 didominasi sektor Pertambangan http://banjarmasin.tribunnews.com/2018/07/26/5-saham-baru-lq45-didominasi-sektor-pertambangan diakses pada 7 November 2018

Usman, B., Nurazi, R, dan Zulkarnain, I. (2012) Analisis Akurasi Bearish Versus Bullish Dengan Menggunakan Candlestick Analysis: Studi Empiris Terhadap Indeks Saham Lq45 (1999-2012). Management Insight, 7 (2): 154-171 ISSN 1978- 3884 http://repository.unib.ac.id/7705/ diakses pada 29 Oktober 2018

Utomo, S. (2017). Trading Saham dengan Menggunakan Fibonacci Retracement. Jakarta : PT. Elex Media Komputindo

Waworudeng, J, H. (2018)_ Analisis Hubungan Pasar Modal Asean Dengan Pasar Modal Indonesia Di Bursa Efek Indonesia. Skripsi.

Zulkarnain, I. (2012) Akurasi Grafik Main Chart Dalam Prediksi Harga Saham Harian : Kasus The Winnest Dan The Losest . Forum Bisnis Dan Kewirausahaan Jurnal Ilmiah STIE MDP http://eprints.mdp.ac.id/668/ diakses pada 29 Oktober 2018. 